public any knowledge, insight and real awareness of what was unfolding into a human tragedy." Really? Regrettably, in the end, this is just an angry book, with familiar targets for the general reader: bureaucrats, governments and doctors (" . . . the medical profession, which itself seems to have been elevated to the sacred"), as well as scapegoats for AIDS "insiders": epidemiologists in general, the $\mathrm{CDC}$ and the National Institutes of Health.

Then at last, near the end, the author informs us about his central concern, which is that in HIV/AIDS prevention and care, the rights of certain individuals are taking precedence over the rights of the larger group. Finally, we are on familiar territory, even if geographical "new found land" is not involved.

The world does face a global crisis in the continuing spread of HIV and its rapidly mounting personal and social burden. How we define a problem largely determines what we do about it. Therefore, despite this book, I am convinced that creative efforts to 'map' this pandemic, including its social geography, could well be important in the evolving effort to give shape and meaning to the global challenge of HIV/AIDS.

Jonathan M. Mann is Francois-Xavier Bagnoud Professor of Health and Human Rights, Professor of Epidemiology and international Health, and Director, International AIDS Center, Hanard School of Public Health, Cambridge, Massachusetts 02.138, USA.

\section{Sex, lives and hormones}

\section{PeterMarler}

Behavioral Endocrinology. Edited by J. B. Becker, S. M. Breedlove and D. Crews. MIT Press: 1992. Pp. 574. \$34.95.

FrANK Ambrose Beach effectively launched the systematic investigation of behavioural endocrinology 40 years before his death with his pioneering 1948 monograph on hormones and behaviour. Two years later he published his famous diatribe, The Snark was a Boojum, berating the so-called 'comparative' psychologists of his day for their myopic focus on the white rat, and urging them, the boojums, to extend their mandate to the animal kingdom at large. The discipline had to wait almost half a century for an allembracing undergraduate text to emerge, a gap now handsomely filled by Behav. ioral Endocrinology, whose editors are all inheritors of the Beach tradition. He would surely have celebrated the degree to which his call for snarks to join forces and endorse the phylogenetic approach has been taken to heart as they explore the way in which hormones exert their manifold effects on the behaviour of organisms.

The 16 chapters by 19 authors, all experts in their field, range from sexual behaviour and sex differences in cognitive functions in humans (C. S. Carter, E.

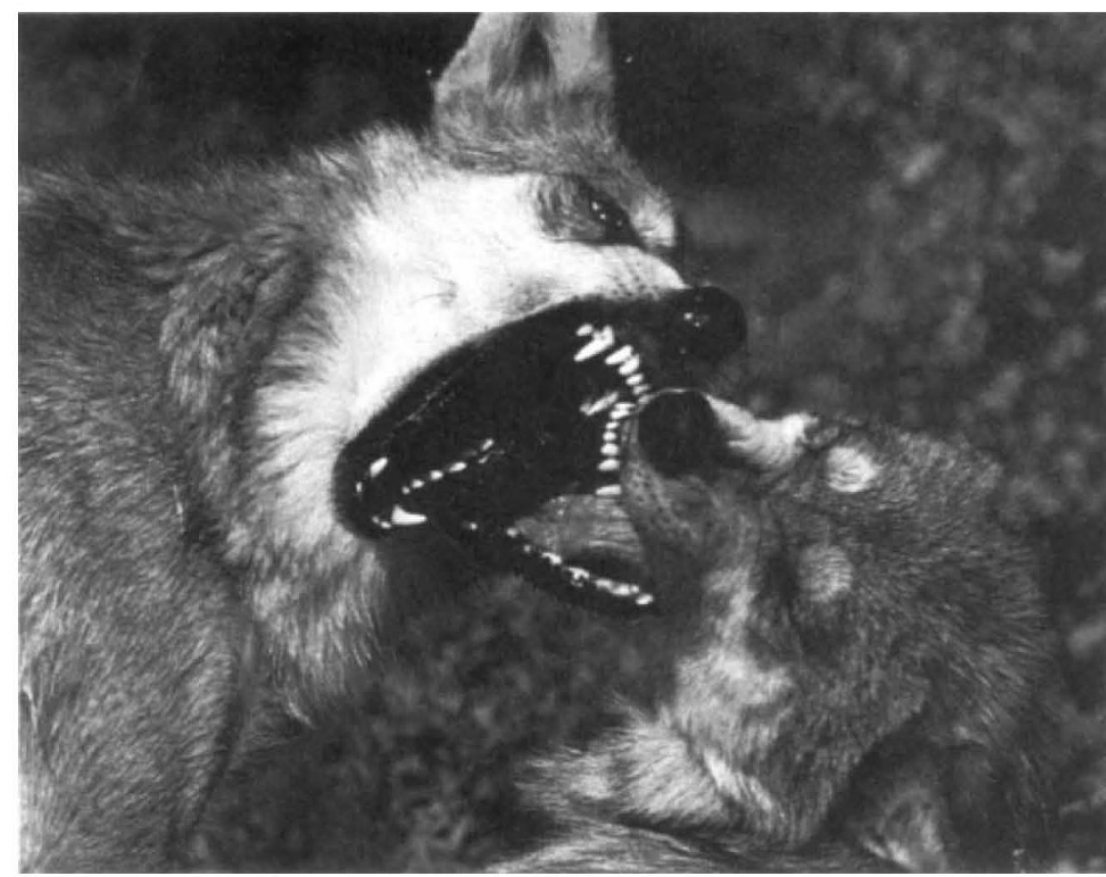

MEXICAN wolves showing affection - the male (left) is giving the female a ritual, painless bite. Taken from Trail of the Wolf by R. D. Lawrence. Key Porter/Verulam, $£ 17.95$, Can $\$ 34.95$.
Hampson, D. Kimura) to the wandering behaviour of the tobacco hornworm and other aspects of invertebrate behavioural endocrinology that illustrate well the advantages, if you are a reductionist, of working with simpler nervous systems (J. W. Truman). Most of the authors are psychologists, and almost inevitably rodents get the most intensive coverage, but the phylogenetic breadth covered is nevertheless impressive. A masterly overview of the behaviour of reptiles and fish (D. Crews) serves to remind us that the causal links between sexual behaviour and gonadal hormones are by no means inviolate, and have been severed repeatedly in the course of evolution. His essay serves as a first step in placing behavioural endocrinology in the functional perspective we associate with modern developments in ecological and evolutionary thinking, although more cross-references to this literature would have been welcome (one searches the bibliography in vain for references that students might want to pursue to the seminal contributions of such biological behaviourists as William Hamilton, John Krebs, John Maynard Smith and E. O. Wilson).

The book is expressly designed as an introductory text that begins from first principles and assumes a minimal background knowledge in biology. It is well designed, has a useful glossary and a bibliography with 1,143 entries. The introductions occasionally fall into the somewhat chatty 'gee whiz' style that sometimes plagues introductory psychology texts (for example: "amazing as it may seem" (p. 12); "the mysterious and fascinating world of sexual behavior" (p. 69); "hormones are not love potions" (p. 69)), but they quickly shed these stigmata of adolescence to grapple with an impressive breadth of subject matter, from molecules to cognition.

Much of the book can serve well as an introduction for students in the neurosciences. Some chapters, such as that of Crews, focus especially on ideas and principles, and others on details of the physiological machinery, such as those on male (M. J. Baum) and female (Carter) sexual behaviour. Chapters by S. M. Breedlove, D. B. Kelly and E. Brenowitz on sexual differentiation of the brain and courtship behaviour deal with sexual dimorphisms, the role of hormones in their development, and the influence of sexual differences on the adult social behaviour of mammals, birds, amphibians and fish. The distinction between activational and organizational effects of hormones on behaviour, fundamental though not necessarily categorical, pervades the entire book. Parental behaviour is authoritatively reviewed by J. S. Rosenblatt, with many illuminating comparisons between mammals and birds, and salutary reminders that some aspects of parental 
behaviour are independent of current hormonal controls.

The prime emphasis on sex is nicely complemented by chapters on nonreproductive behaviours, including a masterly account by R. M. Sapolsky of the psychosomatic relationship, both normal and pathological, between behaviour and the stress response. Other chapters review the role of hormones in the control of aggression (E. P. Monaghan and S. E. Glickman), feeding and drinking (E. M. Stricker and J. G. Verbalis) responses to the physical environment (R. Silver) and behavioural rhythms in oestrous behaviour, and circadian and circannual cycles (L. P. Morin and J. Dark). The appropriateness may be questioned of some of the more speculative material for an undergraduate text. A wide range of human sex differences in motor functions and cognitive abilities known to vary with phases of the menstrual cycle are assumed to have a direct hormonal basis (Hampson and Kimura), a position that some will dispute. A chapter on "Hormonal Influences on Extrapyramidal Sensorimotor Function and Hippocampal Plasticity" (J. B. Becker) documents hormonal effects on the structure and development of regions of the mammalian brain, but the specific mechanisms linking those changes to behaviour are not always clear. The text seems to be enviably free of errors, apart from a label inversion on a table of dissociation of gonadal activity from mating behaviour (p.157) that contradicts the text.

With such a broad mandate, it is more important for the book to be selective than to be comprehensive, but it is tempting to make suggestions for the next edition. New developments in biology at both ends of the reductionistic-holistic spectrum are ready to be incorporated. A new edition should cover more of the pharmacological and molecular approaches to behavioural endocrinology exemplified by the work of T. R. Insel, K. M. Kendrick, E. B. Keverne, B. S. McEwen and D. W. Pfaff, and the environmental and field endocrinology of physiologically minded behaviourists such as B. K. Follett and J. C. Wingfield, that begins to provide us with top-down explanations of how species differences in mating systems and breeding seasons evolve. More could be done to relate the material on aggression and circadian and circannual rhythms to species differences in natural history and life cycles. The truth is that, despite the exhortations of Beach, we have hardly begun to tap the rich source of new insights into the way in which hormones exert their pervasive effects on brain structure and behaviour that the comparative approach can provide.

Peter Marler is in the Animal Communication Laboratory, University of California, Davis, California 95616-8761, USA.
Inheriting responsibility

Laurence D. Hurst

The Engineer in the Garden. By Colin Tudge. Jonathan Cape: 1993. Pp. 398. £17.99.

Gene Future. By Thomas F. Lee. Plenum Press: 1993. Pp. 339. \$24.95, £19.96.

PERHAPS more than any other discipline, genetic engineering figures in the public eye in an equivocal light. On the one hand, white-coated geneticists are caricatured as the devoted fighters of cancer and disease but, by equal measure, they could

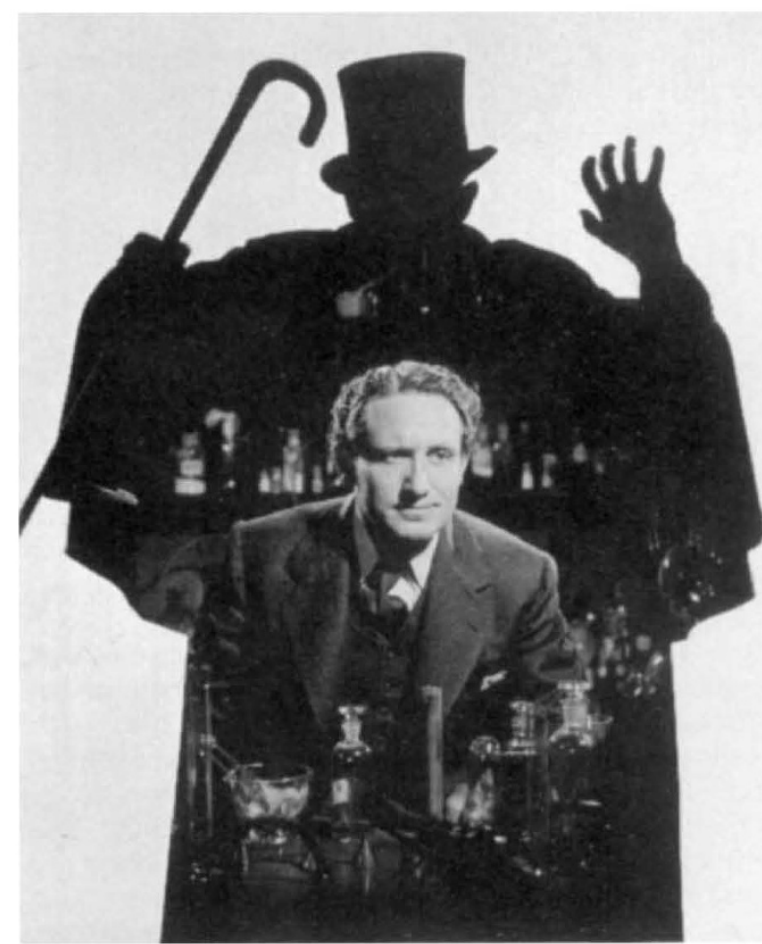

Creators of monsters and marvels - in the eyes of the public, genetic engineers have the power to do enormous good but, by the same token, they also have powers of untold potential evil.

be the cruel experimenters on human embryos and the like. Jekyll and Hyde are alive, well and hard at work creating transgenic monsters and marvels. There is both excitement about what genetic engineering can do and concern about what it could do.

Some of this concern is perhaps more the result of confusion than consideration. Some is not. And hence any book explaining in a fair and accessible fashion just what genetic engineering can do and what the moral issues are is to be warmly received. Unfortunately, authors competent at explaining both the scientific facts and the ethical debate are rare, so two sorts of book tends to emerge: those concentrating on the ethics and those concentrating on the genetics. Gene Future is in the latter class.

The structure of the book is very much of a form. The author starts by discussing DNA and inheritance, then moves on to explain what manipulations can be done, how they can be applied and what of good and bad may come out of it all. His treatment of the facts is always clear and rigorous. If anything, this rigour tends to degrade the text into a series of lists which seem out of place in a 'popular' book. These lists, however, serve Lee's overriding point, namely that the promised genetic revolution is upon us and we must now decide what we want to do with it.

As intimated, Lee does not go on to provide a guiding hand into the moral debate. Although he typically illuminates the scientific facts around the domain of the ethical 눈 issues, the difference between germ line and soma$\div$ tic modification for inst苋 ance, he does not lay out just what the alternative F moral standpoints might be. Instead he describes the research bodies thinking about the issues and the policing authorities watching over the new genetics. Is this intended to reassure us?

One that it does not reassure is Colin Tudge. He argues that the policing agencies are devoid of moral authority. Lawyers are law enforcers, not moral advisers. As might be guessed from this strong attitude, the author is not satisfied simply to lay out the science. It is indeed the moral problems posed by the new genetics that inform much of Tudge's book. His is not, however, the book of an analytical philosopher dissecting the alternatives and deriving the consequences. It is more an advocacy of a moral standpoint and is by turns invigorating and infuriating. Although most of the book is a very accessible introduction to evolutionary and molecular genetics, the author reveals his colours in the final few chapters. Here he puts genetic engineering in the context of the problem of technology as a whole. This in turn he merges with what he sees as the great problem facing us: ever-expanding populations moving us relentlessly towards the brink.

Whereas Lee realizes the same problem and then retreats, Tudge tackles the issue head on. His solution is twofold. First, he suggests a programme for public scientific literacy. Understanding must come before judgement. Citing Christ and John 